\title{
Pro-Angiogenic Role of LncRNA HULC in Microvascular Endothelial Cells via Sequestrating miR-124
}

\section{Dexin Yin ${ }^{\mathrm{a}} \quad$ Yezhou Li ${ }^{\mathrm{a}} \quad$ Changgeng Fu ${ }^{\mathrm{b}} \quad$ Ye Feng ${ }^{\mathrm{c}}$}

aDepartment of Vascular Surgery, China-Japan Union Hospital of Jilin Univers, $4^{\text {th }}$ Department of Surgery, DongFang Hospital of Beijing Universit Chinese $\mathrm{N}$ 'Department of Gastrointestinal Colorectal and Anal Surgery, University, Changchun, China

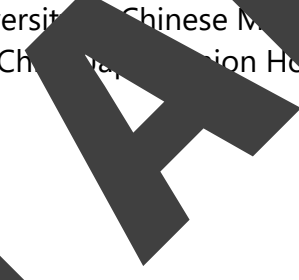

\section{Key Words}

LncRNA HULC • Atherosclerosis • Angiogenesi

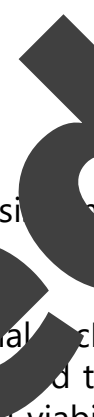

\section{tif} iR- $\mathrm{MCL}-1 \cdot \mathrm{HMEC}-1$ cell

\section{Abstract}

Background/Aims: HULC is various cancers. The present endothelial cells angiogenest

a) RNA that has pro-angiogenic function in $d$ to see the role of InCRNA HULC in normal -related proteins were respectively assessed in human microvascular en helial h. $l-1$ cells after IncRNA HULC was silenced by ShRNA transfection. Cross-regu n betreen IncRNA HULC and miR-124, and between miR-124 and MCL-1 were detectad by Silence of IncRY levels of VEGr HULC indy $\mathrm{d}$ ap os signmeantly reduced viability, migration, tube formation and protein 144 and eNOS in HMEC-1 cells. Meanwhile, silence of IncRNA HMEC-1 cells, as Bcl-2 was down-regulated, Bax was up-regulated H"VLC al VLC worked as a molecular sponge for miR-124, in having miR-124 exhausted. -s, Mu yas a target gene of miR-124. Rescue assay results showed that the effects of HULC olence on HMEC-1 cells growth, migration and angiogenesis were abolished suppression. Similarly, the effects of miR-124 on HMEC-1 cells were abolished $M C L-$ - overexpression. Furthermore, MCL-1 activated PI3K/AKT and JAK/STAT signaling
at sthelial cells. The pro-angiogenic actions of IncRNA HULC may be through sponging miR24 , preventing MCL-1 from degradation by miR-124.

D. Yin and Y. Li contributed equally to this work. 


\section{Cellular Physiology and Biochemistry \begin{tabular}{l|l} 
DOI: 10.1159/000495060 & (c) 2018 The Author(s). Published by S. Karger AG, Basel \\
www.karger.com/cpb
\end{tabular} \\ Yin et al.: Pro-Atherosclerotic Role of LncRNA HULC}

\section{Introduction}

Atherosclerosis is the principal cause of coronary heart disease, ischemic cerebrovascular disease, and peripheral arterial disease. Atherosclerotic plaques narrow the arterial flow lumen leading to ischemic damage and seriously threatening the lives of people. Althour the pathogenesis of atherosclerosis is still unclear, it has been widely accepted tha dysfunction of endothelial cell induced by stimuli, such as hypoxia and endotoxin, initiates the process of atherosclerosis. Healthy endothelium prevents thrombus formation, leukoc adhesion, and smooth muscle cell proliferation, whereas dysfunctioned endothelium, known as activated endothelium has opposing properties [1]. An improved $\mathrm{u}$ of endothelial dysfunction may helpful for development of novel treatment str atherosclerosis.

Long non-coding RNAs (lncRNAs) are a class of transcribed, non-codis (nt), with length longer than 200 nucleotides [2]. Several lncRNAs, like lncRNA MALAT1 [4], and IncRNA GAS5 [5], have been recognized as ano by controlling of endothelial cells proliferation, tube formation, an regulated liver cancer (HULC) is a $500 \mathrm{nt}$ IncRNA. Abery expresst IncRNA HULC is closely related with various cancers, including hepat reino 16$]$, colorectal cancer [7], osteosarcoma [8], and esophageal squamous car 9]. LncRNA HULC has been recognized as a cancer-related lncRNA, and its role ,gen, sis was sporadically revealed, since angiogenesis is a common feat of all cano Two in vitro studies have studied the pro-angiogenic activity of $\operatorname{lncRNA} C$ in liver cer cell [10] and glioma cell [11]. However, whether IncRNA HULC also function in angiogenesis of normal endothelial cell has not been revealed.

Mechanistically, it is believed that lncRN via working as a molecular sponge for which subsequently inhibit miR-
mediated functions [12]. General info a about miRNA involvement in atherosclerosis has been described [13]. Smoking i al with a high miR-124 expression in whole

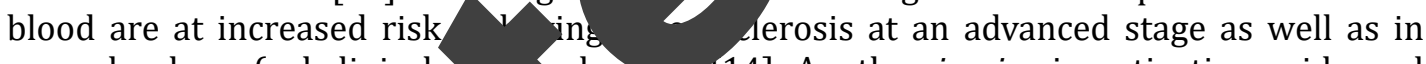
an early phase (subclinical sclerosus 14]. Another in vivo investigation evidenced that homocysteine induce thit sis possibly via promoting the DNA methylation of miR-124 promoter [15] ditionar. creased expression of miR-124 could induce an upregulation of atheroscle s-relared markers, like CD206 [14]. These authors demonstrated miR-124 as an atheroscl ated miRNA.

In the cury endothelial ce to the potential role of lncRNA HULC in atherosclerosis. Then, we focused on er to ween IncRNA HULC and miR-124, to reveal one of the underlying mechan of In HULC's action in endothelial cells angiogenesis.
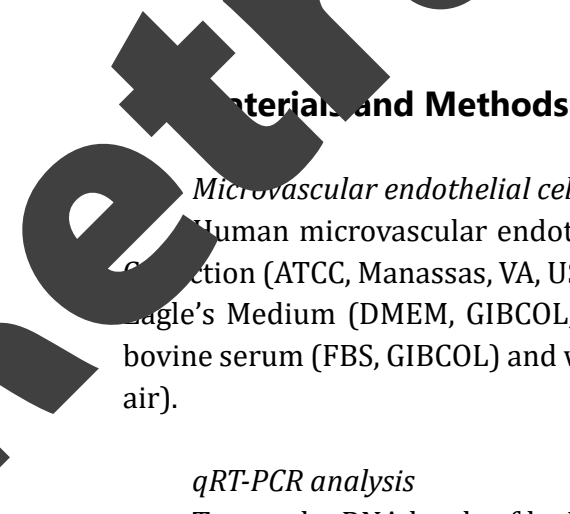

Microvascular endothelial cells culture

uman microvascular endothelial cell line HMEC-1 was purchased from the American Type Culture ction (ATCC, Manassas, VA, USA). The cells were cultured in a culture system using Dulbecco's Modified gle's Medium (DMEM, GIBCOL, Grand Island, NY, USA) supplemented with 10\% heat-inactivated fetal bovine serum (FBS, GIBCOL) and were maintained at $37^{\circ} \mathrm{C}$ in a humidified incubator (with $5 \% \mathrm{CO}_{2}$ and $95 \%$ air).

qRT-PCR analysis

To test the RNA levels of IncRNA HULC and MCL-1, total RNA in HMEC-1 cells was extracted by using Trizol reagent (Life Technologies Corporation, Carlsbad, CA, USA). $5 \mu \mathrm{g}$ of total RNA were subjected to reverse transcription by using the Transcriptor First Strand cDNA Synthesis Kit (Roche, Basel, Switzerland). qRT-PCR was conducted on the ABI PRISM 7500 Real-time PCR System (Applied Biosystems, Foster City,

\section{KARGER}




\section{Cellular Physiology Cell Physiol Biochem 2018;50:2188-2202 \\ \begin{tabular}{l|l|l} 
and Biochemistry Published online: 10 November 2018 & $\begin{array}{l}\text { ○ } 2018 \text { The Author(s). Published by S. Karger AG, Basel } \\
\text { www.karger.com/cpb }\end{array}$ \\
\hline
\end{tabular}}

Yin et al.: Pro-Atherosclerotic Role of LncRNA HULC

CA, USA) by using FastStart Universal SYBR Green Master (Roche). GAPDH served as an internal control in this procedure. To test the RNA levels of miR-372, miR-186, miR-9, miR-122, miR-195, miR-488 and miR124, the miRNAs in HMEC-1 cells were isolated by miRNeasy Mini Kit (Qiagen, Shenzhen, China). Reverse transcription was done in $5 \mu \mathrm{g}$ of total miRNAs by using the Taqman MicroRNA Reverse Transcription Kit (Applied Biosystems). Taqman Universal Master Mix II with the TaqMan MicroRNA Assay (Appli Biosystems) was used for qRT-PCR. The RNA levels of miRNAs were normalized to U6. Fold changes we calculated by relative quantification $\left(2^{-\Delta \Delta C t}\right)$ method.

\section{Cell transfection}

LncRNA HULC was silenced by shRNA transfection. shRNA specific for human lnc ligated into the pGPU6 plasmid which was purchased from Genepharma (Shanghai, China) non-targeting sequences was transfected as a blank control. The specific mimic, inhil or nd controls for hsa-miR-124 were all from Genepharma, and were transfected into ce, type of MCL-1 was ligated into pcDNA3.1 plasmid (Invitrogen, Carlsbad, CA, USA), a plasmid was used as its blank control. For MCL-1 silencing, shRNA specific for $\mathrm{N}$ pGPU6 plasmid (Genepharma). A non-targeting sequence was used as its blan were performed by using lipofectamine 3000 reagent (Life Technolo orporatio der antibiotic-free conditions. At $48 \mathrm{~h}$ of transfection, the culture medium was replace medius ntaining $0.5 \mathrm{mg} /$ ml G418 (Sigma-Aldrich, St Louis, MO, USA). The G418-resistant c wery after four weeks of
culturing.

Cell viability assay

Trypan blue (Beyotime, Shanghai, China) was used vection the viability of HMEC-1 cells. After the indicated transfection, HMEC-1 cells were trans d h w w plants with a density of $5 \times 10^{4}$ cells/well, after which the plants were maintained at for dys. At the indicated time periods, cells were collected by Trypsin/EDTA and centrify- stained by trypan blue solution at room temperature for 3 min. Living cells were coy an scopically. Viability was calculated as \% cell viability $=$ unstained cells (living cells)/total cells $\times$

Apoptosis assay

Cell apoptosis was analyz by unnexin V Apoptosis Detection kit (BD Biosciences, San Jose, CA, USA). The transfected HD 1 cells (_ cells/sample) were double stained with $10 \mu \mathrm{l}$ FITC Annexin $\mathrm{V}$ and $10 \mu \mathrm{l}$ PI. After $30 \mathrm{mir}$ ncuba ion in the dark over ice, the samples were analyzed under the flow cytometry (FACScan $\mathrm{R}$. BD B _ to distinguish early apoptotic cells (FITC-positive and PI-negative) from death cells a optomeells (FITC-positive and PI-positive). Quantification of the apoptotic cell rate was analyze yo software (Tree Star, San Carlos, California, USA). non-traversed cells in the upper side were wiped away carefully by cotton swabs. The cells in lower side Gell 3 USA) with an 8- $\mu$ m pore filter. The transfected HMEC-1 cells $\left(5 \times 10^{4}\right.$ cells/well) were ed in th serum-free medium and were placed in the upper side of chamber. The lower chamber the complete medium (i.e., DMEM medium with $10 \% \mathrm{FBS}$ ). After $48 \mathrm{~h}$ of incubation at $37^{\circ} \mathrm{C}$, tained with crystal violet and were counted microscopically. Relative cell migration was calculated
on the traversed cell numbers from five randomly selected fields, and was respect to the following mula: relative migration $(\%)=($ cell number in experimental group $) /($ cell number in control $) \times 100 \%$.

\section{Tube formation assay}

A 6-well plate was pre-coated with matrigel (BD Biosciences) (1.8 ml/well). After polymerization of matrigel at $37^{\circ} \mathrm{C}$ for $1 \mathrm{~h}, \mathrm{HMEC}-1$ cells were seeded in each well with a density of $1 \times 10^{5}$ cells/well. After 24 $\mathrm{h}$ of incubation in DMEM supplemented with $2 \%$ FBS, numbers of tube-like cell were counted under phasecontrast microscopy. 


\section{Cellular Physiology and Biochemistry \begin{tabular}{l|l} 
DOI: 10.1159/000495060 & $\begin{array}{l}\text { @ } 2018 \text { The Author(s). Published by S. Karger AG, Basel } \\
\text { www.karger.com/cpb }\end{array}$
\end{tabular} \\ Yin et al.: Pro-Atherosclerotic Role of LncRNA HULC}

Reporter vector construct and luciferase reporter assay

The genomic DNA fragment of MCL-1 which contains the predicted miR-124 binding site was amplified by PCR and cloned into pmirGlO Dual-luciferase miRNA Target Expression Vector (Promega, Madison, WI, USA). The predicted binding site in MCL-1 was replaced by a non-targeting sequence to form a control reporter vector. The wild-type $(\mathrm{wt})$ and the mutated-type $(\mathrm{mt})$ of vectors were respectively co-transfect with miR-124 mimic by using lipofectamine 3000 reagent (Life Technologies Corporation). After transfectio Dual-Luciferase Reporter Assay System (Promega) was used for testing the luciferase activity.

\section{ELISA}

After the indicated transfection, cell culture supernatant of each sample was collected a at $1000 \mathrm{~g}, 4^{\circ} \mathrm{C}$ for $15 \mathrm{~min}$. The concentrations of VEGF in the culture supernatant were tes Human VEGF ELISA KIT (CSB-E11718h, Cusabio, Wuhan, China).

\section{RNA immunoprecipitation (RIP)}

wt or mt of HULC was inserted into pcDNA3.1-MS2 plasmid (Addgene, Cam co-transfected with pMS2-GFP (Addgene) and pcDNA3.1-MS2, pcDNA3.1-HULC mt-MS2. Then, the cells were lysed by lysis buffer $(25 \mathrm{mmol} / \mathrm{l}$ Tris- $\mathrm{H}$ H.5), 15 EDTA, 0.5\% NP40, $1 \mathrm{mmol} / \mathrm{l} \mathrm{NaF}, 1 \mathrm{mmol} / \mathrm{l}$ DTT, $100 \mathrm{U} / \mathrm{ml} \mathrm{R}$ inhibitor. The cell lysate was incubated with magnetic beads and GFF MA) by using Magna RIPTM RNA-Binding Protein Immunoprecipitat, antibody (ab200699, Abcam) was used as a blank con After incuba centrifugated at $800 \mathrm{~g}, 4^{\circ} \mathrm{C}$ for $10 \mathrm{~s}$. Subsequently, the co pitated RNA anti-AGO2 RNA IP, cells were transfected with miR-con o* 24 mimic. anti-AGO2 antibody (ab186733, Abcam) was used in this procedure.

\section{Western blot}

HMEC-1 cells were lysed by 1\% Triton 1 Miv PMSF (pH 7.4) over ice for $30 \mathrm{~min}$ for protein extraction. Purity and concentration of pro by the $\mathrm{BCA}^{\mathrm{TM}}$ Protein Assay Kit $(\mathrm{P}$ and was transferred onto a PVDF Tween for $1 \mathrm{~h}$ at room temper $r, \hat{a}$. $4^{\circ} \mathrm{C}$ for the detection of VEG (orb375049), eNOS (orb29 Biotechnology, Santa Cruz, USA), p-PI3K (ab (ab47435), p-Ty al and Stat2 (a 2367 he 0 4 mimic. anti-AGO2 antibody (ab186733, ge, M s were or pcDNA3.1-HULC$\mathrm{l} / \mathrm{l} \mathrm{KCl}, 2 \mathrm{mmol} / \mathrm{l}$ and A-free protease 6. Abcam, Cambridge, (Milu, ore, Bedford, MA). IgG $4^{\circ} \mathrm{C}$ for $6 \mathrm{~h}$, the samples were ranes were then incubated with the secondary antibodies for $1 \mathrm{~h}$ at room $y^{\wedge}$ ing X-ra (Applygen Technologies Inc., Beijing, China). Intensity of bands was quantified using Image oftwa -Rad, CA, USA). 
Fig. 2. Silence of IncRNA HULC represses HMEC-1 cells viability, migration and capillary structure formation. (A) Expression changes of IncRNA HULC with the prolonging of the time were determined by qRT-PCR. (B) Two sequences (\#1 and \#2) of shRNAs specific for IncRNA HULC were respectively transfected into HMEC-1 cells. A non-targeting shRNA (sh-NC) was transfected as a blank control. The RNA levels of HULC were monitored by qRTPCR post-transfection. (C) Viability of HMEC-1 cells was monitored by Trypan blue staining at day 1 to day 4 post-transfection. (D) Protein levels of a poptosis-related factors were measured by Western blot analysis. (E) Relative migration was detected by using a Transwell chamber. (F) Tube formation capacit detected by ch rir cells in ma igel (1) coated

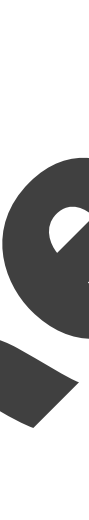

\section{Cincentra of VEGF}

are s gtant

measul by

xpression

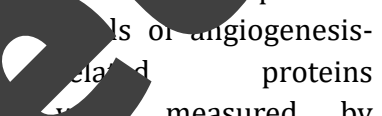
compared to sh-NC group (ANOVA).
A

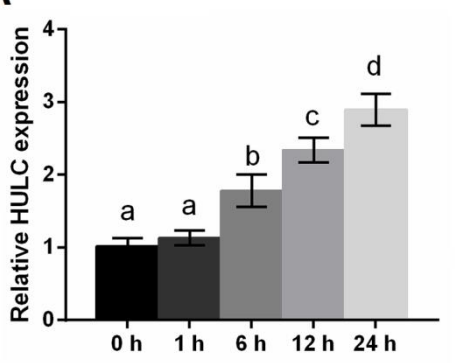

C

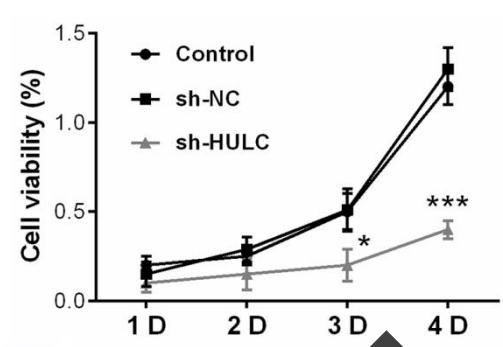

$\mathrm{E}$

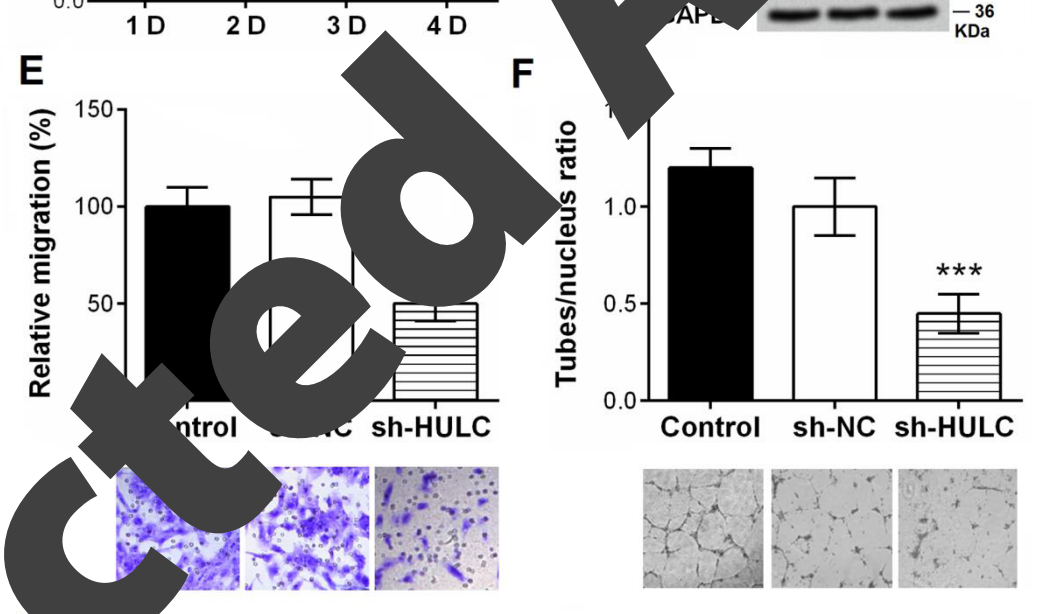

B

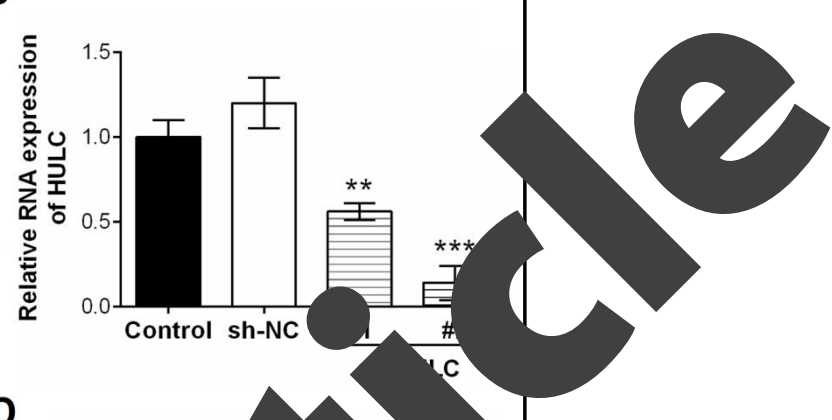

G

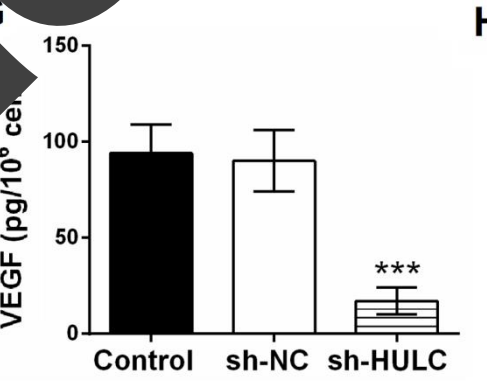

H
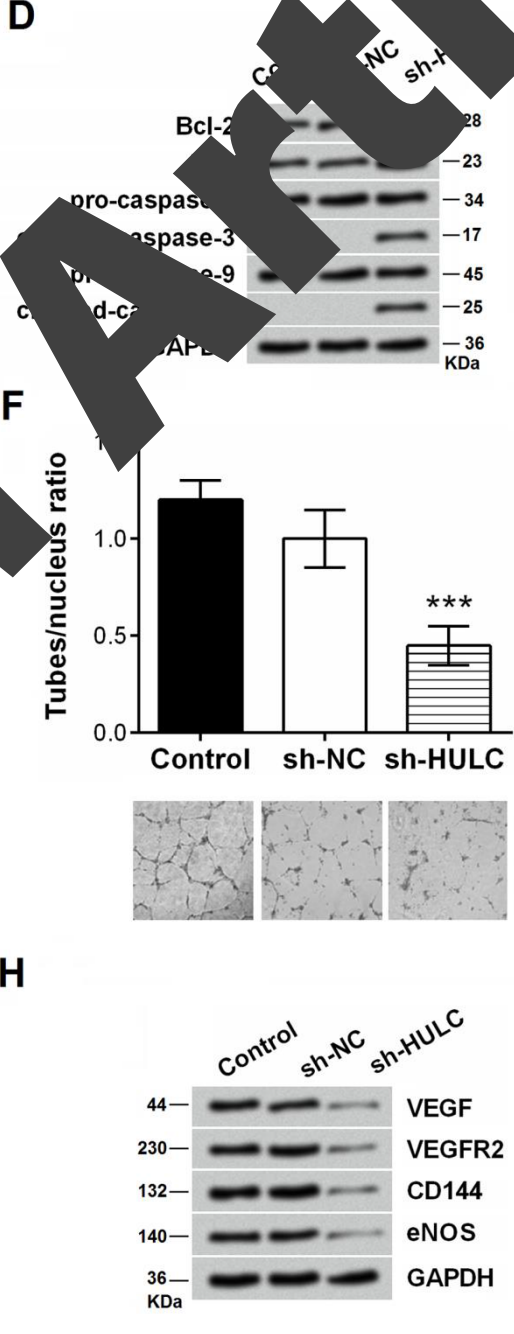

represented as mean \pm SD $(n=3)$. Different lowercase letters above the columns indicate that the mean values of different groups are significantly different $\left(\mathrm{p}<0.05\right.$, ANOVA). ${ }^{*} \mathrm{p}<0.05$, ${ }^{* *} \mathrm{p}<0.01$, and ${ }^{* * *} \mathrm{p}<0.001$

cell rate $(\mathrm{p}<0.001)$ were repressed in sh-HULC group when compared to the sh-NC group (Fig. 2E and 2F). The reduced formation of capillary structure was confirmed in Fig. 2G and $2 \mathrm{H}$, that the concentration of VEGF in culture supernatant $(\mathrm{p}<0.001)$ and the protein levels of VEGF, VEGFR2, CD144 and eNOS were all suppressed by sh-HULC.

\section{KARGER}




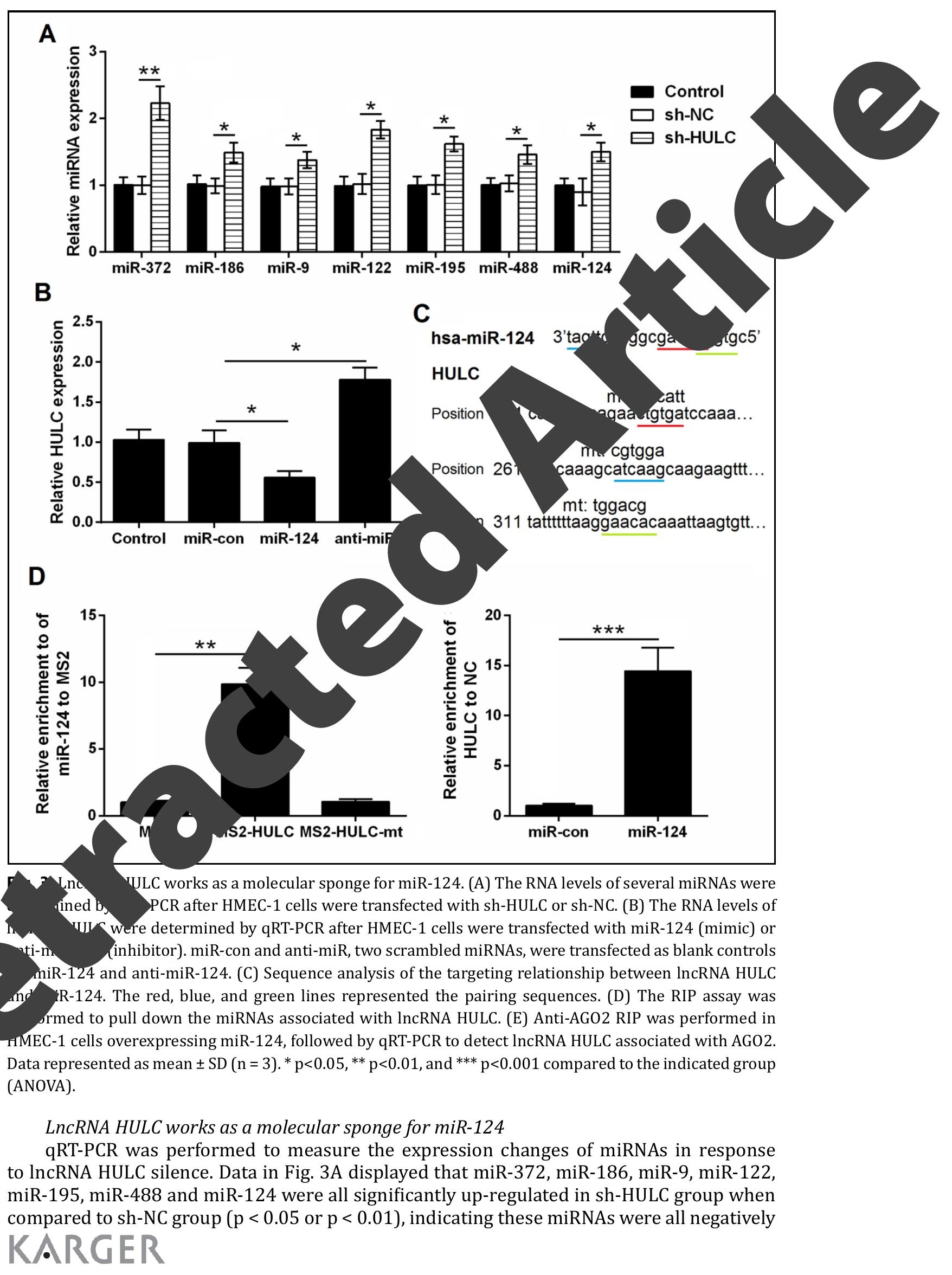




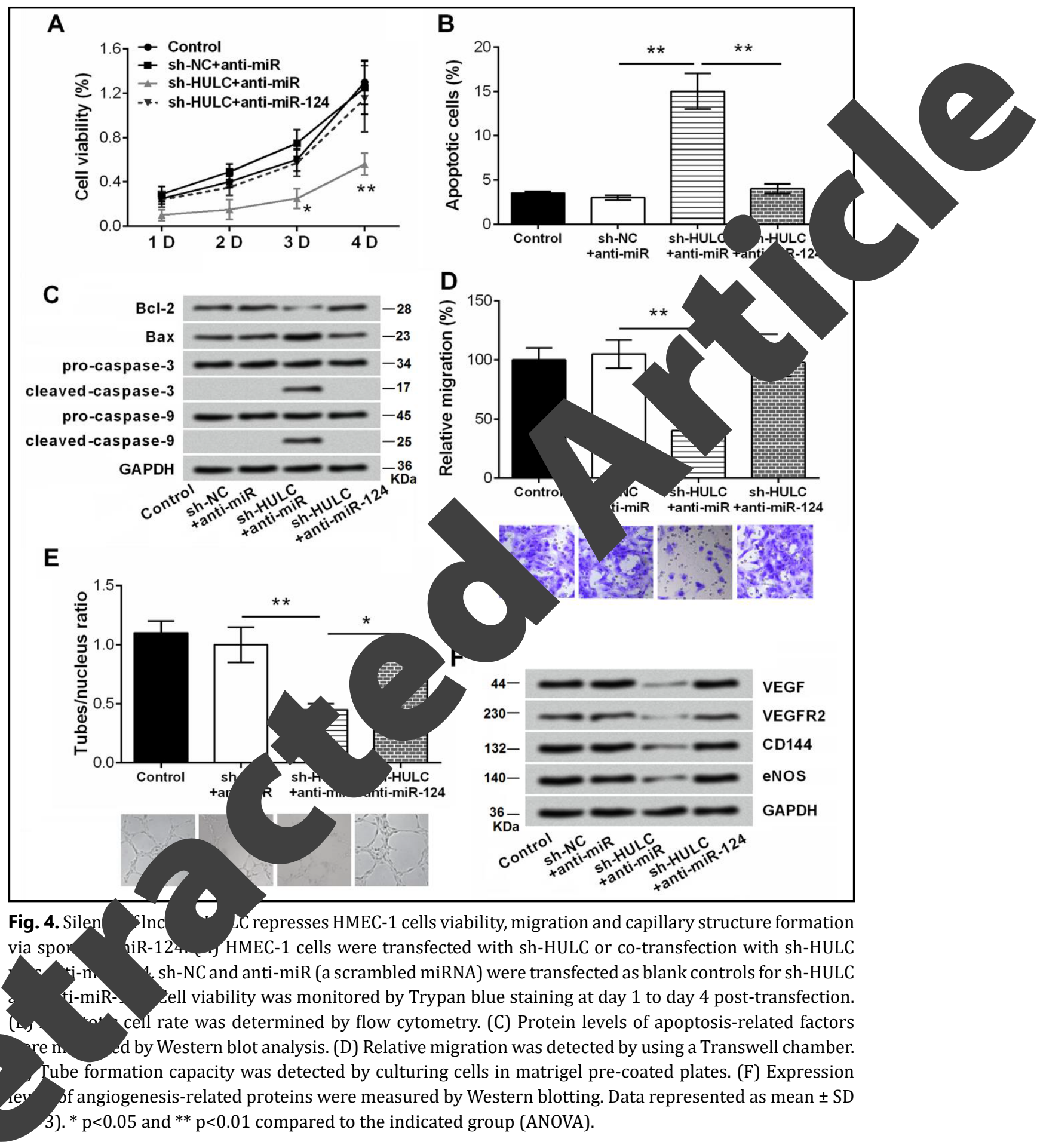

regulated by lncRNA HULC. Considering that miR-124 has been previously reported as an anti-angiogenic regulator [17], miR-124 was selected for further investigation. Next, the expression changes of IncRNA HULC in response to miR-124 dysregulation were tested. Data in Fig. 3B showed that IncRNA HULC was also negatively regulated by miR-124 ( $\mathrm{p}<$ $0.05)$. Sequence analytical results in Fig. $3 \mathrm{C}$ showed that, there existed three sites in lncRNA HULC which could directly bind with miR-124. To further explore the regulatory relationship between IncRNA HULC and miR-124, RNA IP was performed. Fig. 3D showed that the relative 
Yin et al.: Pro-Atherosclerotic Role of LncRNA HULC

enrichment to MS2 was much higher in MS2-HULC group than the MS2 group $(\mathrm{p}<0.01)$. Additionally, endogenous IncRNA HULC pull-down by AGO2 was significantly enriched in miR-124 group as compared to the miR-con group ( $p<0.001$, Fig. $3 \mathrm{E})$. These findings suggested that lncRNA HULC could sponge miR-124, having miR-124 exhausted by binding effects.

Silence of IncRNA HULC represses HMEC-1 cells viability, migration and capillary structure formation via sponging miR-124

Next, HMEC-1 cells were transfected with sh-HULC or co-transfection with shplus anti-miR-124, to see whether miR-124 was involved in the functions of lnd HMEC-1 cells. Fig. 4A displayed that sh-HULC-induced the impairment of cell vi alleviated by anti-miR-124. sh-HULC-induced increase of apoptotic cell rate regulation of Bcl-2, up-regulation of Bax, and cleavage of caspase-3 and -9 by anti-miR-124 (Fig. 4B and 4C). As expected, sh-HULC-induced inhibiti tube-like cell rate (both $\mathrm{p}<0.05$ ), and down-regulations of angiogend were also recovered to the control baseline when anti-miR-124 was 4F).

$M C L-1$ is a target gene of miR-124

It has been reported that miR-124 influenced apoptos MCL-1 survival pathway [18]. Here, we found the mRN

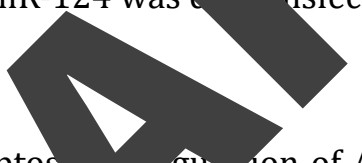
of MCL-1 was down-regulated by miR-124 mi anti-miR-124 transfection (Fig. 5A and 5B). Se that, MCL-1 possessed four sites which co whether MCL-1 could directly bind with miR(GTGAACAC) was selected for use in ly the luciferase activity was significant 124 mimic $(\mathrm{p}<0.05)$. Meanwhile, the by co-transfection with MCI changes were observed in lu 124 mimic, as well as co-t nste data indicated that MCL analysis for testing the lato relationship between IncRNA HULC, miR-124 and MCLvas a tar gene for miR-124. Next, we performed Western blot 1. Fig. 5E showed that $\mathrm{p}$ el of MCL-1 was up-regulated in pc-HULC group and was down-regulated VLCgroup as compared to the corresponding controls respectively. Fig. 5F showe miR-124 \& up a or ured to anti-HULC+anti-miR group. These data together with the above $r$ oned ngs implied an interesting regulation between IncRNA HULC, miR104 na 1 , that lncRNA HULC acted as a molecular sponge for miR-124, preventing fron vadation by miR-124.

represses HMEC-1 cells viability, migration and capillary structure formation via targeting MCL-1

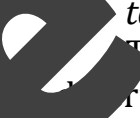
The expression changes of MCL-1 in HMEC-1 cells with the prolonging of the time were mined by performing qRT-PCR. Data in Fig. 6A showed that mRNA level of MCL-1 was gnificantly up-regulated with the time increased $(p<0.05)$. Next, to test the involvement of MCL-1 in miR-124-mediated functions in HMEC-1 cells, miR-124 mimic and/or pc-MCL-1 were transfected into cell. Viability of HMEC-1 cells was significantly reduced by miR-124 mimic at day 4 post-transfection ( $p<0.01$, Fig. 6B). miR-124 mimic transfection resulted in a significant increase in apoptotic cell rate ( $p<0.001$, Fig. $6 \mathrm{C}$ ), a down-regulation of Bcl-2, an up-regulation of Bax, and cleavages of caspase-3 and -9 (Fig. 6D). Additionally, relative migration ( $p<0.05$, Fig. 6E), tube-like cell rate ( $p<0.01$, Fig. 6F), and expression levels of 
angiogenesis-related proteins (Fig. 6G and 6H) were all repressed by miR-124 mimic. More importantly, these above mentioned functions of miR-124 mimic on HMEC-1 cells were all abolished by pc-MCL-1 transfection.

\section{MCL-1 activates PI3K/AKT and JAK/STAT signaling pathways}

For further explore the underlying mechanisms of which MCL-1 promoted HMEC-1 celt angiogenesis, the expression changes of core proteins in PI3K/AKT and JAK/STAT signaling pathways were determined. As shown in Fig. 7A and 7B, sh-MCL-1 transfection reduced

\section{A}

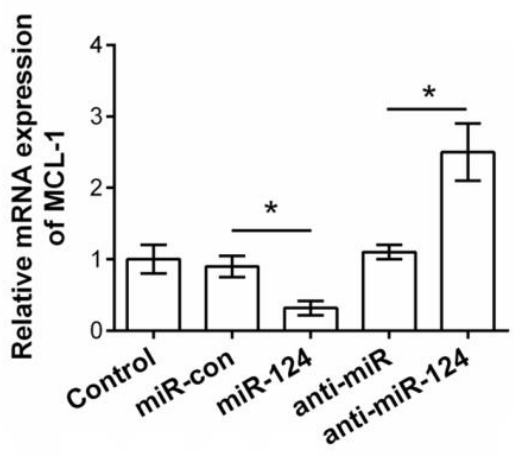

C

hsa-miR-124 3'tagttccaggcgacacttgtgc5'

MCL-1

Position 8971 cccttttagattttggcactgtga

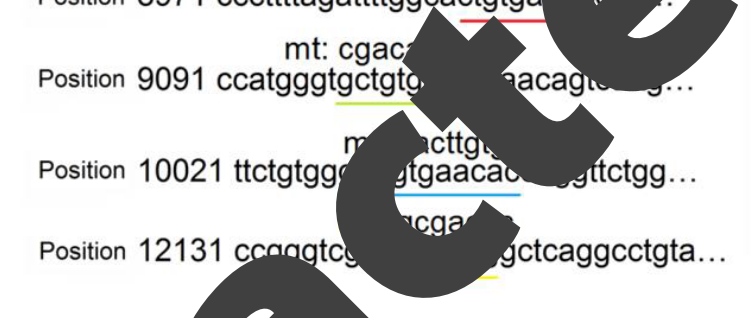

E

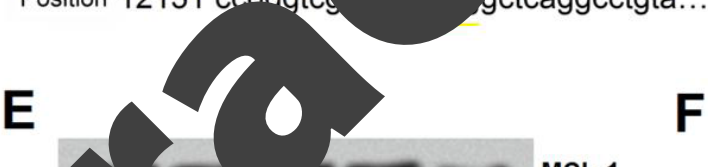

$\mathbf{F}$

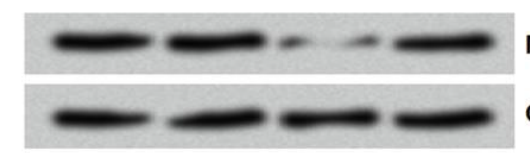

MCL-1

GAPDH

GAPDH
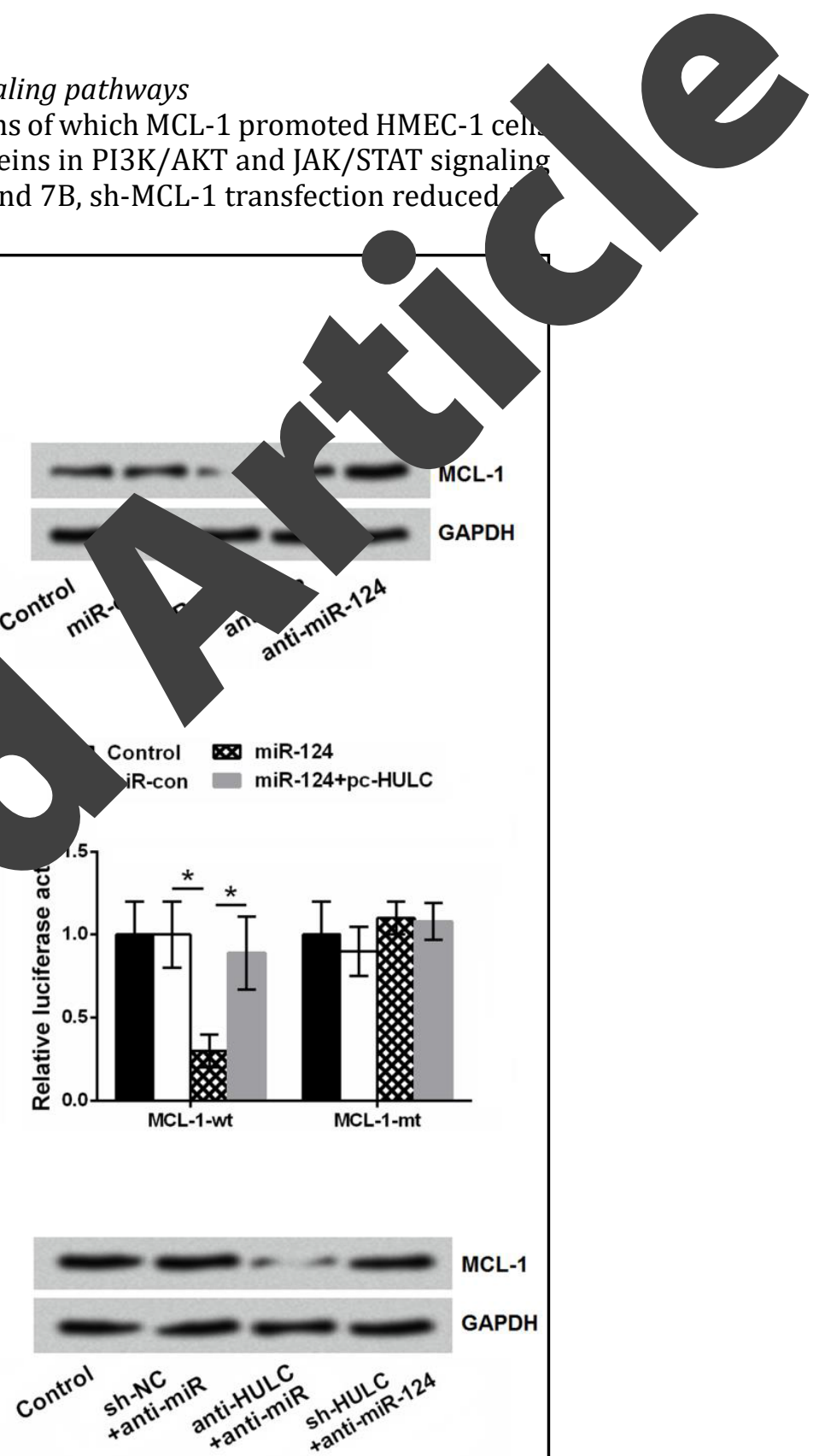

5. MCL-1 is a target gene of miR-124. (A) The mRNA and (B) protein levels of MCL-1 were determined Dy qRT-PCR and Western blot after HMEC-1 cells were transfected with miR-124 (mimic) or anti-miR-124 (inhibitor). miR-con and anti-miR, two scrambled miRNAs, were transfected as blank controls for miR-124 and anti-miR-124. (C) Sequence analysis of the targeting relationship between miR-124 and MCL-1. The red, green, blue and yellow lines represented the pairing sequences. (D) The third predicted binding site in MCL-1 (the sequence colored blue below) was selected to detect whether MCL-1 could bind with miR-124 by using luciferase reporter assay. The protein levels of MCL-1 were measured by Western blot in (E) HMEC1 cells after transfection with pc-HULC or sh-HULC, as well as in (F) HMEC-1 cells after co-transfection with anti-HULC and anti-miR-124. Data represented as mean \pm SD $(n=3) .{ }^{*} p<0.05$ compared to the indicated group (ANOVA). 


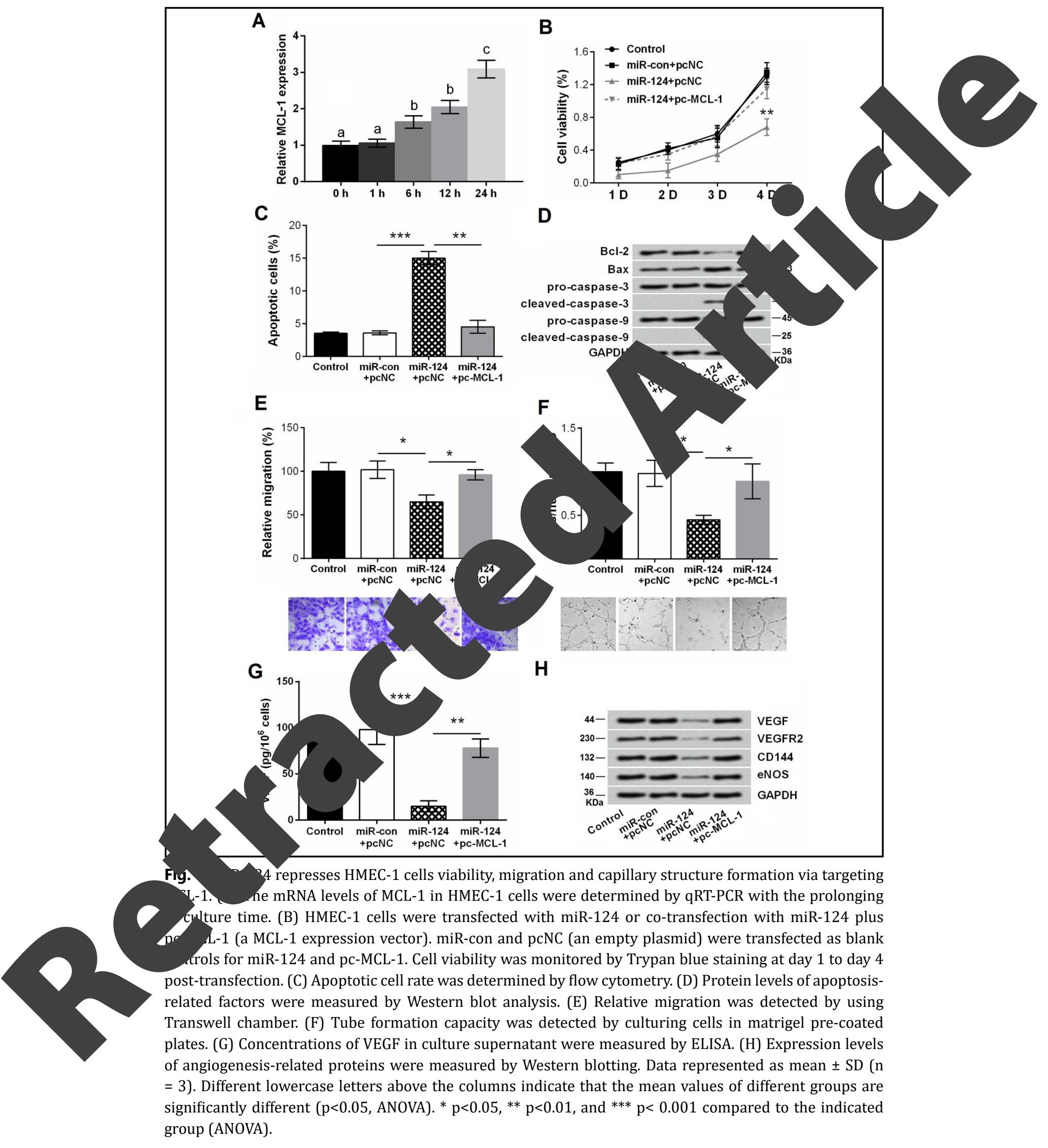




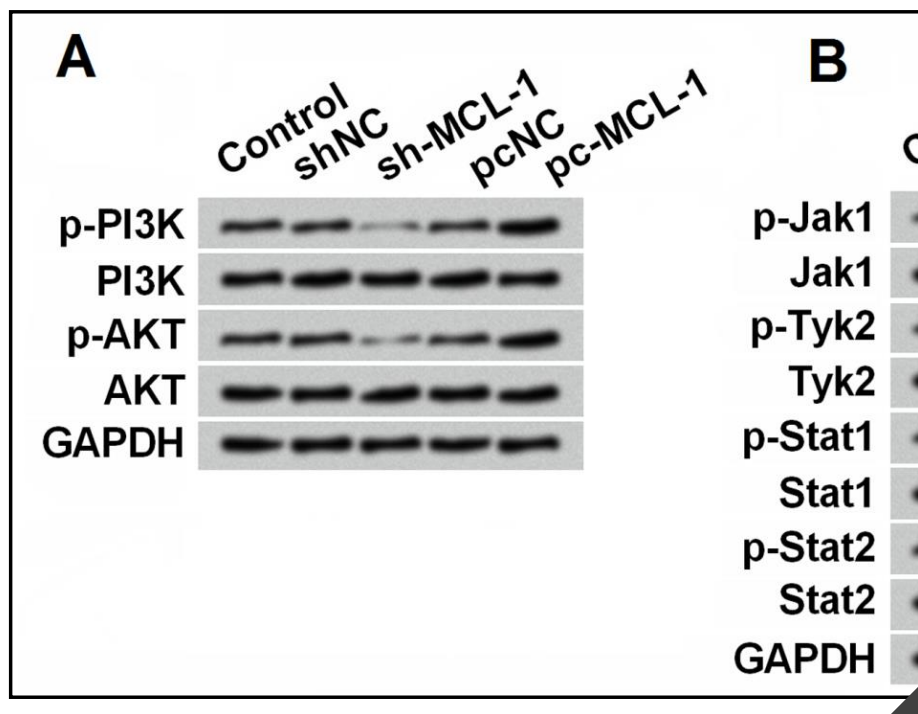

Fig. 7. MCL-1 activates PI3K/AKT and JAK/STAT signaling pathy with pc-MCL-1 or sh-MCL-1 (shRNA specific for MCL-1). pcNC an transfected as blank controls for pc-MCL-1 and sh-MCL-1. The expre AKT pathway were detected by Western blotting. (B) expression pathway were detected by Western blotting.

phosphorylation levels of PI3K, AKT, Jak1, Tyk2 increased the phosphorylation of these prot unaffected either by pc-MCL-1 or by sh-MCI-1.
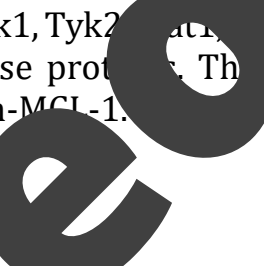

\section{Discussion}

Recently, a growing ny were identified and cl endothelial cell and ma as an atherosclerosis-re HULC represse' tube formatio miR-124 thei 12 reventing MCL-1 (a target gene of miR-124) from degradation by the atherogenic cells like smooth muscle cell, hage [19]. In the present study, we identified IncRNA HULC also NA, which was unstudied previously. Silence of IncRNA ascular endothelial HMEC-1 cells viability, migration and MCL-1 showed accelerating effects on the activation of PI3K/AKT and IAK, Tsignanng pathways in HMEC-1 cells.

do dysfunction is a fundamental event in the process of atherosclerosis. elial as switch from a quiescent phenotype toward one that involves the host onse, during which eNOS switches to generate ROS in appropriate circumstances par endothelial dysfunction [1]. VEGF is a well-known angiogenic growth factor that vasculogenesis $[20,21]$. CD144 is a transmembrane protein involved in endothelial motypic cell adhesion [22]. In the present study, we demonstrated that silence of IncRNA HULC decreased the tube formation capacity of HMEC-1 cells, and reduced the expression of VEGF, VEGFR2 (a receptor of VEGF), CD144 and eNOS, implying lncRNA HULC might contribute to endothelial dysfunction and angiogenesis. As the angiogenesis continues, endothelial cells migration and proliferation lead to the more advanced lesions of atherosclerosis. We additionally demonstrated that silence of IncRNA HULC reduced HMEC1 cells growth and migration. This observation suggested that IncRNA HULC promoted the progression of atherosclerosis via controlling endothelial cells influx and proliferation.

HULC is a multifunctional lncRNA that recent works mainly focused on its role in

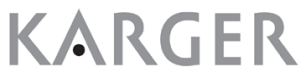


various cancers. Angiogenesis is a common feature of all cancers, thus it is rational that investigators have begun to concern about the role of IncRNA HULC in normal endothelial cells angiogenesis. Increased expression of IncRNA HULC in glioma cells created a bridge between VEGF and VEGFR, as well as between angiogenesis and invasion, which contributed to cancer malignancy [11]. An in vitro investigation also evidenced that IncRNA HULC w capable of promoting tumor angiogenesis in hepatoma cells [10]. However, the present won for the first time discovered that IncRNA HULC also exerted pro-angiogenic functions on normal endothelial cells.

It has been well-accepted that IncRNA function to the regulation of gen expre via acting as endogenous sponges for various miRNAs [12, 23]. LncRNA HUL transcriptionally sponge miR-186 [24], miR-122 [8], miR-372/miR-373 [25], [26], preventing target genes from degradation by these miRNAs, and the in a wide range of cellular process, like cell proliferation, differentiation, $\mathrm{m}$. apoptosis and inflammatory response. Herein, we found that IncRNA HU sponge for miR-124, that lncRNA HULC sequestrated miR-124, pro binding with miR-124. The role of miR-124 observed in this stur previous studies demonstrating miR-124 as an atheroscle related

MCL-1 is a unique member of Bcl-2 family that is di (i.e., Bcl-2, Bcl-xL, Bcl-w and Bfl-1A1), as it holds a consider lo has been shown to be widely expressed in many types of ce a wide range of tissues, such as prostate, breas dometrium MCL-1 exhibited oncogenic functions in color MCL-1 exhibited oncogenic functions in color sancer ce y inhibition of apoptosis and enhancing angiogenesis [29]. In the prese the pro-angiogenic effects of MCL1 on HMEC-1 cells were observed, and our d sug that MCL-1 might be one of the executors for lncRNA HULC, bringing lncRNA 1 int ay significant role in angiogenesis.

Furthermore, various studies sugge cole of PI3K/AKT signaling pathway in the survival and angiogenesis of a dal cells. Activation of AKT activates eNOS, increases the endothelial NO synthas $b$ promotes endothelial cells survival [31] and migration [32], and lead pro ic effect [33]. In addition to PI3K/AKT, JAK/ STAT signaling pathway is als tial inrediating the proliferation of vascular endothelial cells [34], which evidence is a dulating angiogenesis. In the current study, both PI3K/AKT and JAY AT sig ath pathway were shown to be activated by MCL-1 overexpression, while $\mathrm{b}$ blored by MCL-1 suppression. These findings suggest PI3K/ AKT and JAK/STAT ciona ways might be involved in the pro-angiogenic functions of

$\mathrm{L}-1$ (une target gene of miR-124) from degradation by miR-124. More effort is required to

ig check the pro-angiogenic role of IncRNA HULC in vivo and in other types of endothelial especially the primary cells.

\section{Disclosure Statement}

The authors declare that they have no competing interests. 


\section{Cellular Physiology Cell Physiol Biochem 2018;50:2188-2202

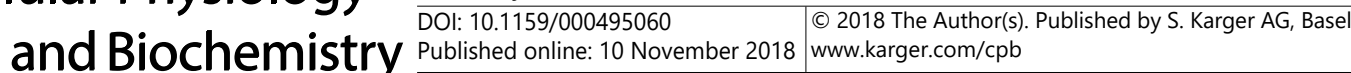 \\ Yin et al.: Pro-Atherosclerotic Role of LncRNA HULC}

\section{References}

1 Deanfield JE, Halcox JP, Rabelink TJ: Endothelial function and dysfunction: testing and clinical relevance. Circulation 2007;115:1285-1295.

-2 Mattick JS, Rinn JL: Discovery and annotation of long noncoding RNAs. Nat Struct Mol Biol 2015;22:5-7.

- 3 Tang YY, Wo LK, Chai H: [Effects of noncoding RNA NRON gene regulation on human umbilical vein endothelial cells functions]. Zhonghua Xin Xue Guan Bing Za Zhi 2013;41:245-250.

-4 Michalik KM, You X, Manavski Y, Doddaballapur A, Zornig M, Braun T, John D, Ponomareva Y, Chen W, Uchida S, Boon RA, Dimmeler S: Long noncoding RNA MALAT1 regulates endothelial cell furation and vessel growth. Circ Res 2014;114:1389-1397.

5 Chen L, Yang W, Guo Y, Chen W, Zheng P, Zeng J, Tong W: Exosomal lncRNA GAS5 regulates the macrophages and vascular endothelial cells in atherosclerosis. 2017;12:e0185406. Sonohara F, Inokawa Y, Hayashi M, Yamada S, Sugimoto H, Fujii T, Kodera Y, Nomoto S. Long Non-Coding RNA HULC and MALAT1 Following the Curative Resection of Hep Sci Rep 2017;7:16142.

7 Shaker OG, Senousy MA, Elbaz EM: Association of rs6983267 at 8q24, HULC rś and serum IncRNAs CCAT2 and HULC with colorectal cancer in Egy natients. Kong D, Wang Y: Knockdown of lncRNA HULC inhibits proliferat apoptosis by sponging miR-122 in osteosarcoma. 2018;119:1050Jiang L, Wang W, Li G, Sun C, Ren Z, Sheng H, Gao H, Wang C, Yu H: Hi chemotherapy resistance and poor prognosis in es Pharmacol 2016;78:333-339.

10 Lu Z, Xiao Z, Liu F, Cui M, Li W, Yang Z, Li J, Ye L, Zhano angiogenesis in liver cancer by up-regulating sphin

11 Zhu Y, Zhang X, Qi L, Cai Y, Yang P, Xuan G, Jiang Y: angiogenesis by regulating ESM-1 via the $P$ Oncotarget 2016;7:14429-14440. Bayoumi AS, Sayed A, Broskova Z, Teoh Noncoding RNAs and MicroR Volny O, Kasickova L, Coufaloy Med Biol 2015;888:155-19

14 de Ronde MWJ, Kok MGY Winther MPJ, Meijers JC individuals suscentible to

\section{seal squamou.}

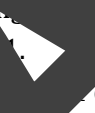
exp,ssion is associated with carcinoma. Cancer Chemother 


\section{Cellular Physiology and Biochemistry Published \begin{tabular}{l|l} 
DOI: 10.1159/000495060 & (c)18 The Author(s). Published by S. Karger AG, Basel \\
www.karger.com/cpb
\end{tabular}

Yin et al.: Pro-Atherosclerotic Role of LncRNA HULC

-23 Cao MX, Jiang YP, Tang YL, Liang XH: The crosstalk between IncRNA and microRNA in cancer metastasis: orchestrating the epithelial-mesenchymal plasticity. Oncotarget 2017;8:12472-12483.

24 Wang Y, Chen F, Zhao M, Yang Z, Li J, Zhang S, Zhang W, Ye L, Zhang X: The long noncoding RNA HULC promotes liver cancer by increasing the expression of the HMGA2 oncogene via sequestration of the microRNA-186. J Biol Chem 2017;292:15395-15407.

-25 Wang WT, Ye H, Wei PP, Han BW, He B, Chen ZH, Chen YQ: LncRNAs H19 and HULC, activated by oxidative stress, promote cell migration and invasion in cholangiocarcinoma through a ceRNA manner. J Hematol Oncol 2016;9:117.

-26 Ma Y, Huang D, Yang F, Tian M, Wang Y, Shen D, Wang Q Chen Q, Zhang L: Long Noncoding RNA Highly Upregulated in Liver Cancer Regulates the Tumor Necrosis Factor-alpha-Induced Apoptos Vascular Endothelial Cells. DNA Cell Biol 2016;35:296-300.

27 Chen G, Magis AT, Xu K, Park D, Yu DS, Owonikoko TK, Sica GL, Satola SW, Ramalingam Doetsch PW, Deng X: Targeting Mcl-1 enhances DNA replication stress sensitivity to co. Invest 2017;10.1172/jci92742.

28 Krajewski S, Bodrug S, Krajewska M, Shabaik A, Gascoyne R, Berean K, Reed JC: Im analysis of Mcl-1 protein in human tissues. Differential regulation of Mcl-1 ana suggests a unique role for Mcl-1 in control of programmed cell de 1319.

29 Lee WS, Park YL, Kim N, Oh HH, Son DJ, Kim MY, Oak CY, Chung CY, Kim HS, Joo YE: Myeloid cell leukemia-1 is associated with tumor pr enhancing angiogenesis in colorectal cancer. Am J Dimmeler S, Fleming I, Fisslthaler B, Hermann C, Bu endothelial cells by Akt-dependent phosphorylation.
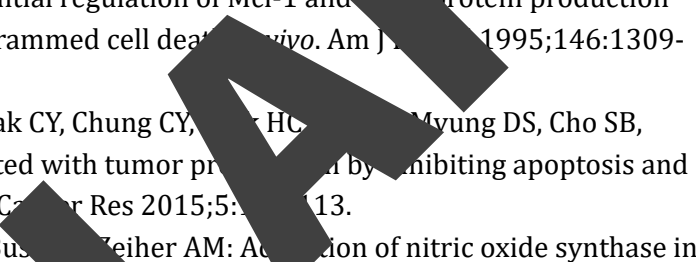
Dimmeler S, Haendeler J, Nehls M, Zeiher AM: Sup interleukin-1beta-converting enzyme (ICE)-like an Exp Med 1997;185:601-607.

32 Dimmeler S, Dernbach E, Zeiher AM: Ph is required for VEGF-induced endotheli

-33 Jiang BH, Zheng JZ, Aoki M, Vg and expression of vascular enc 2000;97:1749-1753.

-34 Singh K, Balligand JL, Fis in cardiac myocytes and and 2 (ERK1/ERK2) and

$$
\text { ion tosis by nitric oxide via inhibition of }
$$
99:399:601-605.
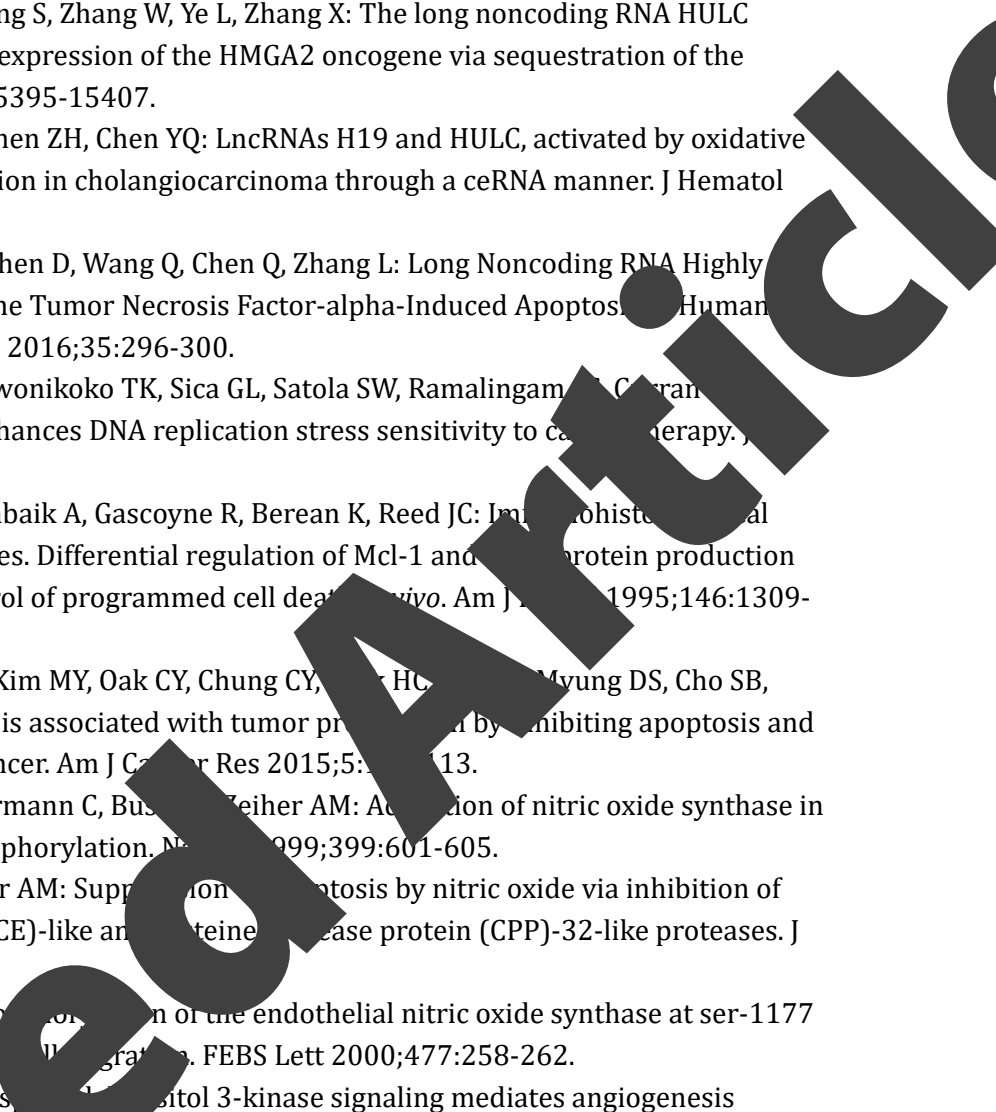
or tre endothelial nitric oxide synthase at ser- 1177 FEBS Lett 2000;477:258-262. itol 3-kinase signaling mediates angiogenesis grow.... . Kelly RA: Regulation of cytokine-inducible nitric oxide synthase rovasc ${ }^{\wedge}$ ar endothelial cells. Role of extracellular signal-regulated kinases 1

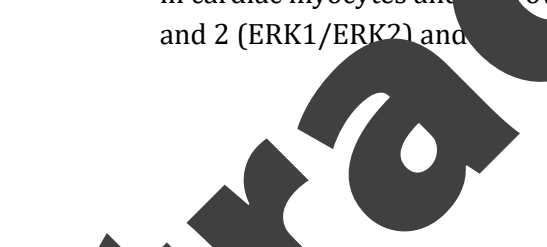

